\title{
Effect of Employee Oriented Human Resource Management Practices on Employees' Counterproductive Work Behaviors
}

\author{
Zelalem Gebretsadik Estifo Luo Fan Naveed Ahmad Faraz \\ School of Management, Wuhan University of Technology, Wuhan, P.R.China, 430070
}

\begin{abstract}
This research investigated the link between employee-orientated human resource management (EOHRM) counterproductive work behaviors targeted at individual members and organization in Ethiopia. Relaying on social exchange theory, organizational support theory, signaling theory and relevant literatures we examined how employee-oriented HRM practice affects counterproductive work behaviors by using perceived organizational support as a mediator. Data had been obtained from 555 workers and 150 supervisors from eight companies in Ethiopia. Partial least squares structural equation modeling (PLS-SEM) methods via SmartPLS has been used to determine the hypothesized links pertaining to employee-oriented HRM and counterproductive work behavior directed towards individual members and the organization. Final results confirmed that perceived organizational support fully mediated the relationship between employee-oriented HRM and counterproductive work behaviors. The impact of employee-oriented HRM on counterproductive work behavior -organizational via perceived organizational support were stronger than the impact of employee-oriented HRM on counterproductive work behavior- individual (interpersonal). These findings suggest that organizations may minimize(reduce) employees' counterproductive work behavior by putting into action employee-oriented HRM practices that would uplift perceived organizational support that finally prevent the tendency to act against the organization and its members.
\end{abstract}

Keywords: Employee-oriented human resource management, perceived organizational support, counterproductive work behavior

DOI: $10.7176 / \mathrm{JRDM} / 56-02$

Publication date: June $30^{\text {th }} 2019$

\section{Introduction}

Most of the literary works indicates counterproductive work behavior(CWB) is truly a significant problem to companies all over the world and definitely will remain to be, because the involvement levels in a number of forms has grown with time(Bennett et al. 2018). Counterproductive work behavior (CWB) are actually understood to be 'scalable actions and behaviors that workers participate in which usually deter from company goals and objectives or well-being and include behaviors that bring about undesirable consequences for the organization or its stakeholders' (Ones \& Dilchert 2013). CWB as a set happen to be seen as a neglect with respect to guidelines and values of businesses and contemporary society by large (Ones 2018). The management of counterproductive work behavior at work is of becoming challenge for companies throughout the world since many of these behaviors can be bad for their particular economic well-being (Appelbaum et al. 2007). Whether or not the counterproductive work behavior is direct or subconscious, whether it entails sexual intimacies nuisance, criminal behavior, gossip distribution, and company destruction or otherwise, illegal organizational behavior has detrimental effects for the companies and/or people connected with them (Appelbaum et al. 2007). Counterproductive work behavior incorporate worker delinquencies that include not really pursuing the manager's guidelines, deliberately scaling down the process step, showing up late, carrying out small fraud coupled with not caring for fellow workers with dignity and/or behaving rudely with colleagues (Galperin 2002).

For years, analysts in organizational behavior have looked into counterproductive work behavior that is certainly detrimental to the concerns associated with a business as well as members (Robinson \& Bennett 1995). Even though, researchers spend their valuable time to look into the very fact out of numerous aspect, most recent research signifies that counterproductive work behavior is ever-increasing and causes a severe and costly challenge pertaining to businesses worldwide (Detert et al. 2007; Dunlop \& Lee 2004). In accordance with this, innovative strategies/approaches intended for handling counterproductive work behavior (CWB) in businesses are actually wanted as are more sophisticated kinds of counterproductively appearing in companies like for example crime collusion and cyber-loafing(Ones 2018). Not too long ago, research indicates counterproductive work behavior is the largest danger from the inside relating to organizational continued existence in sub-Saharan Africa. Counterproductive work behavior is not just a danger pertaining to the present organization but also it is functioning as repulsive mechanism pertaining to foreign direct investment in sub-Saharan Africa as it can be observed right from Kroll's world-wide fraud survey (Kroll 2016). Sub-Saharan Africa has for a long time been areas with the greatest fraud burden, which has not changed. It consists of the biggest portion of organizations impacted by at least one fraud. Additionally, it experienced among the maximum average losses to fraud within the last 1 year of any region(Kroll 2016).In spite of such extreme epidemic of counterproductive work behavior, 
there exists lack of specific research focusing on sub-Saharan African and look into strategies for curving the occurrence of counterproductive work behavior.

This research intends to investigate the relationship between employee-oriented HRM and counterproductive work behaviors geared towards individual and organization. EOHRM entails corporate social responsibility (CSR) actions that specifically answer staff members and their families desires that are far above statutory requisites, and it's hence viewed as an essential form of socially sustainable HRM (Shen \& Jiuhua Zhu 2011). Currently this concern is far more evolved towards a term known as Philanthropy towards/with workers which usually entails provisions of child or elderly care centers, pension programmes, internship intended for young, worker voluntarism and giving (Turker 2018).

The connection between EO-HRM practice and counterproductive work behavior directed at individual and organization(CWB- I \& O) could be articulated depending on social exchange theory, which claims that relationships are made around norms of reciprocity through which favors are reciprocated accordingly; positive favors can be obtained in substitution for good contribution, while poor favors in substitution for poor contributions(Cropanzano \& Mitchell 2005). In addition to, Social exchange theory forecasts that, in response to pleasant initiating actions, targets will certainly tend to respond in kind simply by participating in better reciprocating replies and/or lesser unfavorable reciprocating reactions (Cropanzano et al. 2016). Therefore , through this theoretical angle, it could be hypothesized that when the business participate in employee-oriented HRM (EOHRM) that deals with staff members and their family needs and wants and so goes way over and above what is actually expected legally, workers will certainly reciprocate the obligation via putting on pleasant behaviors and by staying away from involving in counterproductive work behaviors.

This research aims to expand the literature on the effect of EOHRM practice upon counter productive work behavior. EO-HRM practice as a shield device against counterproductive work behavior has never been researched even though grounded theories in management plainly reinforce such types of adverse relationship between the two. It is high time now to examine the bond in between EO-HRM practice and counterproductive work behavior in the context of sub-Saharan Africa where recent surveys unveiled that the treat to business survival is soaring from the inside. To the best of our understanding, no former research has looked into the relationship between EO-HRM practices on a counterproductive work behavior. Being a new start, this study will certainly contribute to the existing HRM literature by developing a theoretical comprehension and providing new empirical evidences in describing the effects of EO-HRM upon dealing with counterproductive work behavior. To this end, a conceptual model is developed as a base for additional research of this uncharted territory.

\section{Conceptual Background and Hypotheses}

\subsection{Employee Oriented HRM and Counterproductive Work Behavior}

Shen \& Jiuhua Zhu (2011) formulated the concept socially responsible HRM for capturing CSR guidelines aimed at the company's internal and external customers. They suggest that socially responsible HRM consists of labor law-related legal compliance HRM, employee-oriented HRM, and general CSR facilitation HRM. In our research, we concentrate on employee-oriented HRM in analyzing workers' counterproductive work behavior. There exists a continuous controversy in the research with regards to the right course of action in which HRM system influence on the behavior of workers on the job (Newman et al. 2016). Earlier research have commonly used the social exchange theory as a ground to evaluate how 'high performance' HRM procedures impact worker attitudes as well as behaviors (Snape \& Redman 2010; Sun et al. 2007). Research by Newman et al. (2016) fairly recently verified that social exchange theory best suited to clarify for what reason workers reply to socially responsible HRM, considering the fact that EO-HRM rewards workers straightaway.

The social exchange theory suggests the fact that obligations are produced because of reciprocated social exchange involving two parties within a relationship. Social exchange transaction is started by company whenever they take care of their particular staff in an exceedingly excellent manner and then provide them with financial or perhaps socio-emotional support (Gould-Williams 2007). Thus, employees become pleased to reply good treatment they have been conceded by taking part in behavior that particularly will benefit the business. According to the social exchange theory, Newman et al. (2016) forecasted that the organization's usage of employee-oriented human resource management strategies that enhance the wellbeing as well as satisfy needs of workers will certainly bring about workers to reciprocate by means of OCB which usually benefits the business because they develop higher levels of company identification. Studies have showed that people take care of the procedural and distributive equity parts of experiences (Greenberg 1990). Workers may possibly form an identity of themselves and their company and this identity guides behavior (Ashforth \& Mael 1989; Dutton \& Dukerich 1991). If the workers observe their particular company as caring and socially responsible, it might influence their self-concept such that they may abstain from counterproductive behaviors (Viswesvaran et al. 1998). Alternatively, a notion that their company cares only for economic out comes may result in workers becoming considerably more permissive about counterproductive work behaviors. 
In this particular case, employee oriented HRM can be accepted as a good starting actions on the part of the business, which usually pushes the employee to reciprocate by means of pleasant actions like OCB, and abstaining from participating in counterproductive work behaviors. Consequently, the following hypothesis is postulated:

Hypothesis 1a: Employee oriented HRM has a strong negative effect on counter productive work behavior individual.

Hypothesis 1b: Employee oriented HRM has a strong negative effect on counter productive work behavior organizational

\subsection{Employee- Oriented HRM and Perceived Organizational Support}

In social sciences, various research explain worker behaviors in relation to Blau's social exchange theory(Blau 1964).This basic principle clarifies worker behaviors like a two-way communication between person and company. Employees get some pleasant or perhaps unfavorable messages from companies and then engage in some pleasant or perhaps destructive behaviors as a response to the organization(yildiz \& Alpkan 2015). Taking into consideration this kind of relationship within the social exchange theory it is possible to infer that employees' organizational level perceptions are predictors of attitudes and in turn these attitudes are predictors of behaviors(Blau 1964). Further, social exchange advocates argue that resources received from others are more extremely appreciated if they happen to be based upon discretionary decision instead of conditions over and above the donor's control. Such voluntary aid is welcomed as an indication that the donor genuinely values and respects the recipient (Blau 1964; Cotterell et al. 1992; Blau 1964).

Within the principle of organizational support theory, three basic kinds of perceived favorable treatment received from the company (i. e., justness, supervisor support, and company prizes and job conditions) should certainly boost POS (Eisenberger et al. 1986). Shore \& Shore (1995) suggested that human resources practices revealing recognition of worker efforts ought to be decidedly identified with POS. Therefore, the subsequent hypothesis is suggested:

Hypothesis 2: Employee oriented HRM has a significant positive effect on perceived organizational support.

\subsection{Perceived organizational support and counterproductive work behavior}

Perceived organizational support (POS) is the extent to which employees believe that "their company cherishes their contributions and cares about their well-being" (Eisenberger et al. 1986; Rhoades et al. 2002). Organizational support theory stats that the degree of perceived organizational support influences employees beliefs regarding their legitimacy as company members (Ashforth et al. 2008; Dutton et al. 1994) and that when staff members feel themselves to be genuine organizational members they have an inclination to emotionally and psychologically connect themselves to the company (Rhoades et al. 2001). Former empirical investigation by researchers portrayed the reverse connection between perceived organizational support and counterproductive work behavior tailored both at individual and organization (Eder \& Eisenberger 2008; Colbert et al. 2004; Ferris et al. 2009; Ferris et al. 2009; Hochwarter et al. 2003; Shanock \& Eisenberger 2006; Thau et al. 2009)

In similar fashion, when ever workers recognize that their earlier contribution and individual well-beings has been appreciated by company, employees will likely then minimize their counterproductive work behavior and enhance their effort and hard work in the interests of company (Shore \& Shore 1995).In the on the contrary, research in Pakistan verified that insufficient company support has contributed to counterproductive work behavior among workers of telecommunications and IT businesses (Khan et al. 2013). This research showed that procedural unfairness and unjust human resource policies have resulted in emotional effects among employees, like anger and despair. Then, they involved in counterproductive work behavior like verbal threaten, intentionally performed sluggish, and work theft. It was offering reassurance that how organizational support can combat counterproductive work behavior in work environment. In that capacity, it can be articulated that POS, which arises from EOHRM practice, is likely to lessen employee's inclination to engage in CWB. Hence, we propose:

Hypothesis 3a: Perceived organizational support has a significant negative effect on counter productive work behavior -individual

Hypothesis 3b: Perceived organizational support has a significant negative effect on counter productive work behavior -organizational.

\subsection{Perceived organizational support as a mediator of the relationship between employee oriented HRM on counter productive work behavior}

There is a typical impression that employees notice high performance work practices (HPWPs) like an individualized commitment toward them, an investment in them, and as tribute of their determination, which they will then reply through correspondingly pleasant attitudes and behavior toward the business (Hannah \& Iverson 2004). Salancik \& Pfeffer (1978) explained that, "a range of employee-oriented CSR initiatives- such as 
offering life insurance coverage, preventing layoffs, allowing a work-life equilibrium, providing job autonomy, and maintaining equitable remuneration-are essential for taking good care of the health and well-being of workers, and have positive effects upon workers".

In accordance with the research of Vatankhah et al. (2017), empowerment, reward and promotion show organization's worry about airline flight attendants' health and well-being and further career advancement opportunities. In accordance with signaling theory, result of their research further suggest that, airline flight attendants reply favorably towards the help and support they obtain from the organization by displaying behavioral outcome which is in accordance with organizational objective. To put it differently, POS contributes to reduce tendency to commit any act of CWB (Vatankhah et al. 2017). In similar fashion, Spence (1973) relaying on signaling theory expressed that high performance work practice transmits an indication to workers the fact that organization cherishes it workers which intern would bring about pleasant response from workers in terms of perceived organizational support (POS) plus much more involved in OCB and reduce CWB.

Generally, the implementation of employee-oriented HRM in the work place transmits signals of help coming from company resulting in less counterproductive work behavior. From the stand point of management, companies focusing on tackling counterproductive work behavior at work, should certainly create work environment which foster POS by using high performance work practices (Vatankhah et al. 2017). Results of this research claim that POS would definitely decrease the magnitude of counterproductive work behavior, which increase managerial concern to find techniques by which POS is improved (Vatankhah et al. 2017). On the contrary, workers with the impression of unsupportive organization appear to be more involved in counterproductive work behavior (Alias et al. 2013).

Staff members would understand the application of EO-HRM as pleasant indication of assist from the company. Their positive evaluation of company cues and the a sense of POS would definitely result in reciprocate favorably by way of averting to engage in counterproductive work behavior such as absenteeism, fraud, sabotage, drug use and sexual harassment at work. According to aforementioned understanding, this research intends to tests the conceptual model that investigates the mediating effect of POS in the relationship between EO-HRM and counterproductive work behaviors. Furthermore, Study of such relationship in light of Signaling theory is advised in the current literature (Alfes et al. 2013; Mostafa \& Gould-Williams 2014; Connelly et al. 2011) .

Hypothesis 4a: Perceived organizational support mediates the negative effect of employee oriented HRM on counter productive work behavior -individual

Hypothesis 4b: Perceived organizational support mediates the negative effect of employee oriented HRM on counter productive work behavior -organizational

Depending on the theoretical views and scientific research mentioned earlier, a framework for this research is suggested. As portrayed in Figure 1, counterproductive work behavior geared towards particular individual and organization was the criterion variable with perceived organizational support as a mediator and employeeoriented HRM an independent variable. Precisely, the framework shows that employee oriented HRM are directly and indirectly linked to CWBs via perceived organizational support.

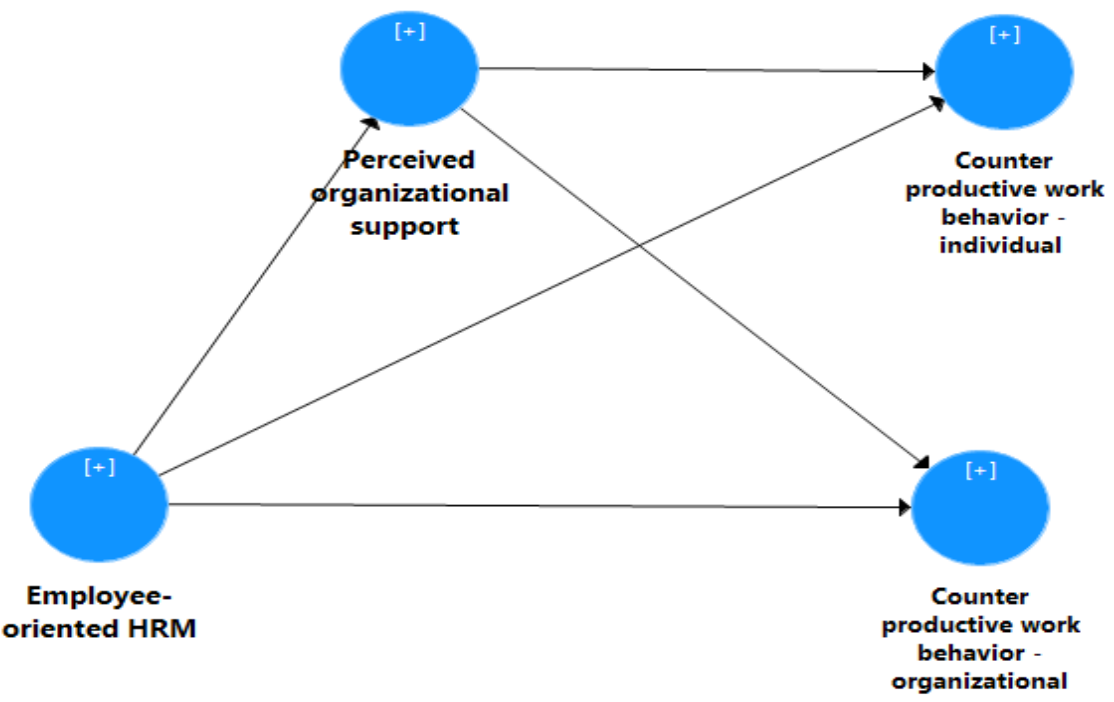

Figure 1. Theoretical Framework. 


\section{Methodology}

\subsection{Participants and Procedures}

A questionnaire survey was used to gather data from corporate social responsibility oriented companies situated in Addis Ababa, Ethiopia. An overall of 705 completely filled survey forms had been gathered from frontline workers and their supervisors in eight companies. Out of 705 participants, 555 were employees and 150 were supervisors. In the survey questionnaire, workers were asked about the extent of EOHRM practice in their respective organizations and their degree of POS. While supervisors were asked about the extent to which their employee involved in counter productive work behavior. The sample of study consists of $61.4 \%$ males and 36 . $8 \%$ females. Furthermore, $44.3 \%$ of the respondents were between $18-29$ years of age accompanied by $33.5 \%$ who were of aged between 30-39 years. Most of the respondents, 71. $2 \%$, had a bachelor's degree and $13.9 \%$ participants had a master's degree. $45.6 \%$ of the participants had 1 to 5 years of tenure.

\subsection{Measures}

The 34 measures utilized for the current study had been adopted from earlier research. To assess employeeoriented HRM, four items were adapted from Shen \& Benson (2016) and three additional items were adapted from (Rasool 2017). A sample item is "My company adopts flexible working hours and employment programs achieving work-life balance". Nineteen items measuring counterproductive work behavior directed at individual and businesses had been taken from Bennett \& Robinson (2000); for instance, "Falsified a receipt to get reimbursed for more money than you spent on business expenses. "Similarly, eight items of Eisenberger et al. (1986) were used to measure perceived organizational support, "My company cherishes my personal contribution to its well-being."

\subsection{Common-Method Bias}

Harman's single factor test was used to check for the prevalence of common method bias in this particular study. According to this technique, if the variance of the first factor is below fifty percent then it can be an indicator of no common method bias (Podsakoff et al. 2003). The result confirmed that one factor's variance of $26.90 \%$ which was lower than cutoff threshold. Subsequently, we can infer that there were no worrying common method bias issues in connection to this study.

\subsection{Data Analysis}

Data analysis had been carried out in three phases. Data screening, validation of the measurement model and analysis of the structural model (Hair $\mathrm{Jr}$ et al. 2016). The process involves arranging, categorizing, tabulating, and checking out raw data and altering them into a body of facts appropriate for making decisions and hypothesis testing(Burns et al. 2014). A survey questionnaire forms the empirical basis for this investigation. Following collecting data through the questionnaire, EpiData software program has been utilized for data entry and documentation. SPSS version 23. 0 and SEM with PLS path modeling employing Smart-PLS3 version-3. 2 . 7 have been employed to analyze the primary data to be able to look into the constructs of the hypotheses.

\section{Results}

\subsection{Measurement Model}

Assessment of reflective measurement models incorporates composite reliability to gauge internal consistency, individual indicator reliability, and average variance extracted (AVE) to assess convergent validity(Hair Jr et al. 2017). Evaluation of reflective measurement models also incorporates discriminant validity. Cross-loadings, and particularly the heterotrait-monotrait (HTMT) ratio of correlations are often used to analyze discriminant validity(Hair Jr et al. 2017).

\subsubsection{Internal Consistency Reliability}

The more common qualifying criterion for internal consistency is Cronbach's alpha, which offers an estimate of the reliability depending on the intercorrelations of the observed indicator variables (Hair Jr et al. 2017). The ideal Cronbach's alpha values range from 0.60-0.90. Stemming from Cronbach's alpha's limitations in the population, it is better suited to utilize another type of measure of internal consistency reliability, which is known as composite reliability (Hair Jr et al. 2017). The acceptable composite reliability values range from 0.600.90.Based on both of these assessments, all constructs showed a very good internal consistency reliability. Table 1 contains internal consistency reliability measures (Cronbach's alpha, composite reliability, and rho_A).

\subsubsection{Convergent Validity}

To ascertain convergent validity, we examined the external loadings of the indicators, in addition to the average variance extracted (Hair Jr et al. 2017). A common rule of thumb is that the (standardized) outer loadings should be 0.708 or higher. With regard to AVE a value of 0.50 or higher is acceptable(Hair Jr et al. 2017). Those constructs with external loadings much less that the stipulated thresholds had been taken out. Two reflective indicators of perceived organizational support [POS34(0.566), POS36(0. 586) ], two reflective indicators of 
employee-oriented [EO-HRM42(0.430), EO-HRM(0.467)] and one reflective indicator of counterproductive work behavior geared to the organization [DOD28(0.514)] are among the wiped out indicators. Other indicators with external loadings between 0.5-0.7 are kept in the model because the composite reliability and AVE are above the suggested tolerance value and the removal do not add value(Hair Jr et al. 2017). The AVE values of the latent variables used in this study are higher than the specified threshold standard of 0.5 (Hair Jr et al. 2017).

Table 1 shows the convergent validity values(outer loadings and AVE).

Table 1: Internal Consistency Reliability and Convergent Validity Assessment

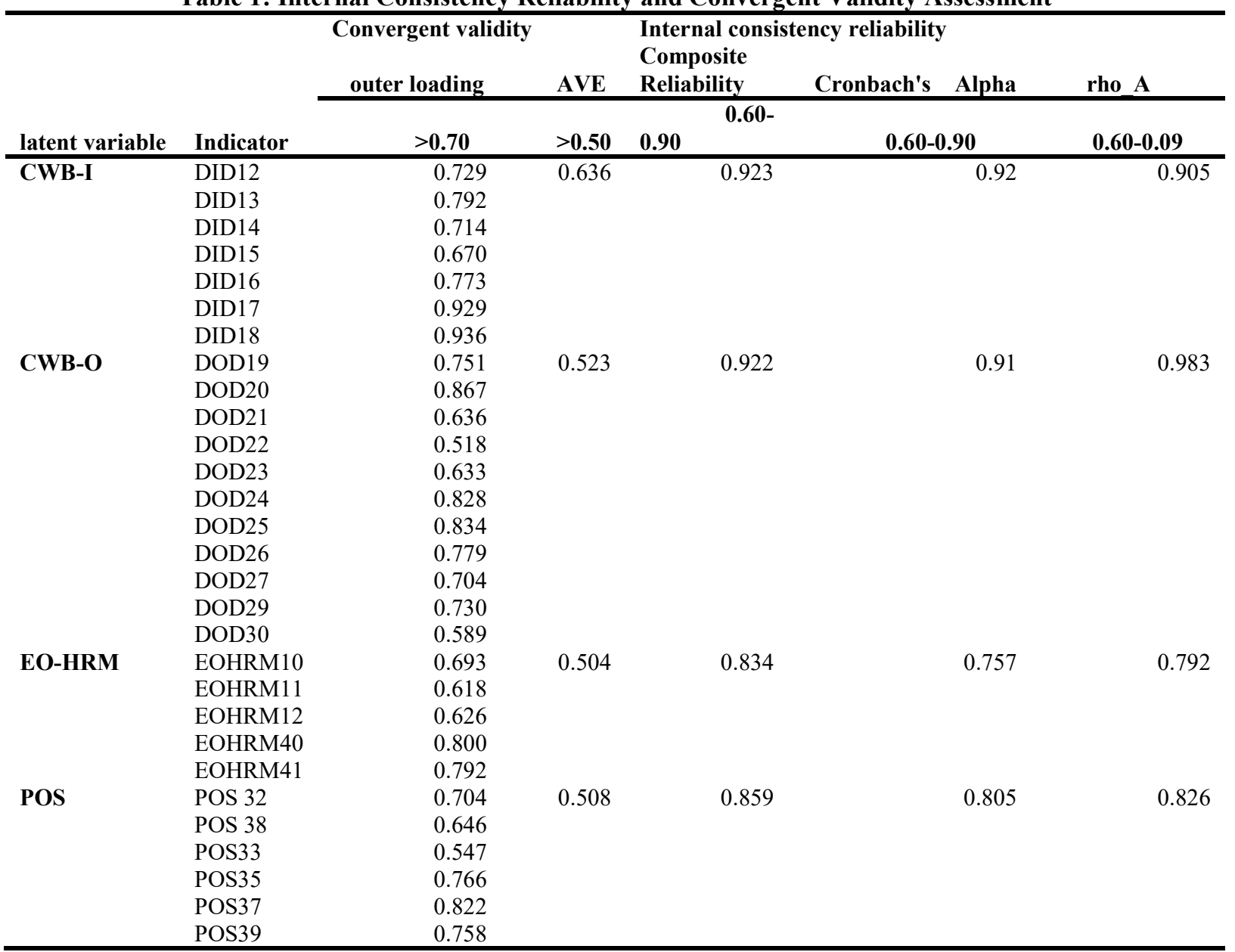

Note. $C W B-I=$ Counterproductive work behavior-individual ; $C W B-0=$ Counterproductive work behaviororganizational ; EOHRM =Employee oriented HRM;POS=Perceived organizational support; DID=Destructive individual deviance; $D O D=$ Destructive organizational deviance.

\subsubsection{Discriminant Validity}

To assess the discriminant validity, we employed the cross loadings of the indicators (Hair Jr et al. 2017). Particularly, an indicator's external loading over the affiliated construct must be higher than all of its loadings upon various other constructs (i.e., the cross loadings). The existence of cross loadings that surpass the indicators' external loadings signifies a discriminant validity issue. Table $\mathbf{2}$ displays the results of discriminant validity assessment based on cross-loading evaluation. From this result we can see that discriminant validity is achieved since each indicators of the latent variables loads more to their own construct than others.

As the robustness scan for discriminant quality, we examined the heterotrait-monotrait ratio (HTMT) of the correlations (Hair Jr et al. 2017). The HTMT technique is the most up-to-date and as well, safe and effective way to examine discriminant validity (Hair Jr et al. 2017). As presented in Table 3, the confidence interval of each and every HTMT value does not include the value 1 for all levels of constructs, as a result verifying that discriminant quality is established. Depending on these two assessments, each and every constructs established adequate discriminant quality. 
Table 2: Discriminant Validity based on Cross-loading Evaluation

\begin{tabular}{|c|c|c|c|c|}
\hline & CWB-I & CWB-O & EO-HRM & POS \\
\hline DID12 & 0.729 & 0.521 & 0.023 & -0.023 \\
\hline DID13 & 0.792 & 0.626 & -0.022 & -0.066 \\
\hline DID14 & 0.714 & 0.415 & 0.006 & -0.056 \\
\hline DID15 & 0.670 & 0.368 & 0.062 & 0.008 \\
\hline DID16 & 0.773 & 0.526 & -0.031 & -0.131 \\
\hline DID17 & 0.929 & 0.606 & -0.069 & -0.127 \\
\hline DID18 & 0.936 & 0.660 & -0.075 & -0.135 \\
\hline DOD19 & 0.631 & 0.751 & -0.047 & -0.153 \\
\hline DOD20 & 0.714 & 0.867 & -0.130 & -0.199 \\
\hline DOD21 & 0.574 & 0.636 & -0.004 & -0.056 \\
\hline DOD22 & 0.124 & 0.518 & -0.038 & -0.055 \\
\hline DOD23 & 0.287 & 0.633 & -0.017 & -0.075 \\
\hline DOD24 & 0.401 & 0.828 & -0.104 & -0.133 \\
\hline DOD25 & 0.553 & 0.834 & -0.075 & -0.106 \\
\hline DOD26 & 0.502 & 0.779 & -0.030 & -0.109 \\
\hline DOD27 & 0.564 & 0.704 & -0.021 & -0.089 \\
\hline DOD29 & 0.480 & 0.730 & -0.030 & -0.069 \\
\hline DOD30 & 0.521 & 0.589 & 0.010 & -0.070 \\
\hline EOHRM10 & -0.008 & -0.038 & 0.693 & 0.478 \\
\hline EOHRM11 & -0.023 & -0.045 & 0.618 & 0.361 \\
\hline EOHRM12 & -0.006 & -0.071 & 0.626 & 0.373 \\
\hline EOHRM40 & -0.107 & -0.085 & 0.800 & 0.673 \\
\hline EOHRM41 & -0.042 & -0.049 & 0.792 & 0.590 \\
\hline POS 32 & -0.097 & -0.090 & 0.542 & 0.704 \\
\hline POS 38 & -0.115 & -0.071 & 0.392 & 0.646 \\
\hline POS33 & -0.081 & -0.105 & 0.339 & 0.547 \\
\hline POS35 & -0.099 & -0.166 & 0.537 & 0.766 \\
\hline POS37 & -0.135 & -0.177 & 0.620 & 0.822 \\
\hline POS39 & -0.078 & -0.067 & 0.598 & 0.758 \\
\hline
\end{tabular}

Note. EOHRM $=$ Employee oriented HRM;POS=Perceived organizational support $;$ DID=Destructive individual deviance ; $D O D=$ Destructive organizational deviance.

Table 3: Discriminant Validity based on Heterotrait-Monotrait Ratio (HTMT)

\begin{tabular}{|c|c|c|c|c|c|c|c|}
\hline \multirow[b]{2}{*}{ Relationships } & \multirow{2}{*}{$\begin{array}{l}\text { Original } \\
\text { Sample } \\
\text { (O) }\end{array}$} & \multirow{2}{*}{$\begin{array}{l}\text { Sample } \\
\text { Mean (M) }\end{array}$} & \multirow{2}{*}{$\begin{array}{l}\text { Standard } \\
\text { Deviation } \\
\text { (STDEV) }\end{array}$} & \multirow{2}{*}{$\begin{array}{l}\text { T Statistics } \\
(|\mathrm{O} / \mathrm{STDEV}|)\end{array}$} & \multirow{2}{*}{$\begin{array}{l}\mathbf{P} \\
\text { Values }\end{array}$} & \multicolumn{2}{|c|}{$\begin{array}{l}\text { Confidence } \\
\text { interval Bias } \\
\text { corrected [ upper } \\
\text { and lower limit] }\end{array}$} \\
\hline & & & & & & $2.50 \%$ & $97.50 \%$ \\
\hline $\begin{array}{l}\text { CWB-O } \rightarrow \text { CWB- } \\
\text { I } \\
\text { EO-HRM } \rightarrow\end{array}$ & 0.692 & 0.692 & 0.037 & 18.867 & 0.000 & 0.617 & 0.762 \\
\hline $\begin{array}{l}\text { CWB-I } \\
\text { EO-HRM }>\end{array}$ & 0.079 & 0.108 & 0.021 & 3.830 & 0.000 & 0.057 & 0.083 \\
\hline CWB-O & 0.090 & 0.123 & 0.026 & 3.449 & 0.001 & 0.067 & 0.094 \\
\hline POS $\rightarrow$ CWB-I & 0.117 & 0.137 & 0.038 & 3.120 & 0.002 & 0.065 & 0.180 \\
\hline POS $\rightarrow$ CWB-O & 0.165 & 0.179 & 0.040 & 4.135 & 0.000 & 0.100 & 0.239 \\
\hline POS $>$ EO-HRM & 0.873 & 0.874 & 0.032 & 27.396 & 0.000 & 0.803 & 0.929 \\
\hline
\end{tabular}

Note. EOHRM =Employee oriented HRM;POS=Perceived organizational support ; $C W B-I=$ counter productive work behavior -individual; $C W B-O=$ counter productive work behavior-organizational

\subsection{Structural Model}

To check the mediating role of POS in the bond between EOHRM and counterproductive work behavior, we adhered to the techniques suggested by (Hair Jr et al. 2017). Structural model examination criteria's like prediction relevance $(\mathrm{Q} 2)$, explained variance $\left(\mathrm{R}^{2}\right)$, assessments of the path coefficients had been used to check both indirect and direct impact of employee-oriented HRM on CWBs targeted at individual members and organization. 
Confirming the particular configuration settings is very important, because a unwise selection of alternatives can bring about considerably biased standard error reports (Ringle et al. 2012). Consequently, under calculate sub command, basic settings of bootstrapping had been configured as follows: subsample: 5000, checked do parallel processing; sign changes: no sign changes; amount of results: complete bootstrapping. In the advanced settings; under confidence interval options: bias-corrected and accelerated(BCa) bootstrap had been selected; test type - two tailed; significance level -0 . 05. With regard to partial lest square basic settings: weighting scheme- path; Maximum iterations- 300; and stop criterion: $10^{\wedge}-7$.

Table 4 shows the bootstrap t-value, bootstrap confidence interval, estimate of explained variance, $p$ value, beta coefficient and prediction relevance in our direct effect structural model. Besides, Fig. 2 and Figure 3 presents details about structural model outcomes via bootstrapping. As indicated in Table 4, the explained variance $\left(\mathrm{R}^{2}\right)$ of the model endogenous latent Variable are CWB-I(0. 127), CWB-O (0. 137) and POS (0. 530). This show that, our model explains 12.7, 13.7 and 53 percent of the changes in CWB-I, CWB-O and POS, respectively. According to Cohen (1988), our model's coefficients of determination values for the endogenous constructs can be categorized as moderate for CWB-I \&O and large effect for POS. Similarly, there was clearly support for adequate prediction relevance of the direct effect model because Table 4 demonstrate a $Q^{2}$ value bigger than zero(Hair Jr et al. 2016).

The structural model result verifies that there is no significant direct relation between EOHRM and counterproductive work behavior targeted both at individual and organization $(\mathrm{H} 1 \mathrm{a} \& \mathrm{~b})$ as shown in Table 4, beta $=0.107, \mathrm{t}=1.340, \mathrm{p}=0.180, \mathrm{CI}[-0.055,0.236]$ and beta $=0.097, \mathrm{t}=1.081, \mathrm{p}=0.280, \mathrm{CI}[-0.077,0.243]$ respectively. On the other hand, there is significant relation between EOHRM and Perceived organizational support $\left(\mathrm{H}_{2}\right)$ as shown in Table 4, beta $=0.727, \mathrm{t}=29.702, \mathrm{p}<0.01, \mathrm{CI}[0.676,0.771]$. The results also shown that there is a negative relationship between Perceived organizational support and counterproductive work behavior directed at individual and organization $\left(\mathrm{H}_{3 \mathrm{a} \& \mathrm{~b}}\right)$ beta $=-0.203, \mathrm{t}=2.958, \mathrm{p}<0.003, \mathrm{CI}[-0.315,-0.066]$ and beta $=-0.236, \mathrm{t}=3.167, \mathrm{p}<0.002, \mathrm{CI}[-0.363,-0.090]$, respectively.

Additionally, perceived organizational support fully mediates the negative relationship between EOHRM and counterproductive work behavior targeted both at individual and organization $\left(\mathrm{H}_{4 \mathrm{a}} \mathrm{b}\right)$ since the indirect effect via the mediator (POS) is significant while the direct effect of EO-HRM to counterproductive work behavior at both targets are not significant. Indirect effect; EO-HRM $\rightarrow$ POS $\rightarrow$ CWB-I and CWB-O has beta $=-0.148, t=2$. $888, \mathrm{p}<0.004, \mathrm{CI}[-0.232,-0.048]$ and beta $=-0.172, \mathrm{t}=3.122, \mathrm{p}<0.002, \mathrm{CI}[-0.266,-0.066]$, respectively.

Direct effect; EO-HRM $\rightarrow$ CWB-I and $\mathrm{O}$ beta $=0.107, \mathrm{t}=1.340, \mathrm{p}=0.180, \mathrm{CI}[-0.055,0.236]$ and beta $=0$.

097, $\mathrm{t}=1.081, \mathrm{p}=0.280, \mathrm{CI}[-0.077,0.243]$, respectively. Table 5 shows the bootstrap t-value, $\mathrm{p}$ value, bootstrap confidence interval, and beta coefficient in our indirect effect structural model.

Table 4: Hypothesis Testing- Direct Effect

\begin{tabular}{|c|c|c|c|c|c|c|c|c|c|}
\hline \multirow{2}{*}{$\begin{array}{l}\text { 嵒 } \\
\text { 荧 } \\
\text { 密 }\end{array}$} & \multirow[b]{2}{*}{ Relationships } & \multirow{2}{*}{$\begin{array}{l}\text { Original } \\
\text { Sample } \\
\text { (O) }\end{array}$} & \multirow{2}{*}{$\begin{array}{l}\text { Beta } \\
\text { coefficient }\end{array}$} & \multirow{2}{*}{$\begin{array}{l}\text { Standard } \\
\text { Deviation } \\
\text { (STDEV) }\end{array}$} & \multirow{2}{*}{$\begin{array}{l}\text { T Statistics } \\
\text { (|O/STDEV|) }\end{array}$} & \multirow{2}{*}{$\begin{array}{l}\mathbf{P} \\
\text { Values }\end{array}$} & \multicolumn{2}{|c|}{$\begin{array}{l}\text { Confidence } \\
\text { interval Bias } \\
\text { corrected [ upper } \\
\text { and lower limit] }\end{array}$} & \multirow[t]{2}{*}{ Inference } \\
\hline & & & & & & & $2.50 \%$ & $97.50 \%$ & \\
\hline $\mathrm{Hla}$ & EO-HRM $>$ CWB-I & 0.100 & 0.107 & 0.075 & 1.340 & 0.180 & -0.055 & 0.236 & NS \\
\hline \multirow{2}{*}{$\begin{array}{l}\mathrm{H} 1 \mathrm{~b} \\
\mathrm{H} 2\end{array}$} & EO-HRM $>$ CTWB-O & 0.089 & 0.097 & 0.082 & 1.081 & 0.280 & -0.077 & 0.243 & \multirow{2}{*}{$\begin{array}{l}\text { NS } \\
\text { Supported }\end{array}$} \\
\hline & EO-HRM $>$ POS & 0.725 & 0.727 & 0.024 & 29.702 & 0.000 & 0.676 & 0.771 & \\
\hline \multirow{2}{*}{$\begin{array}{l}\mathrm{H} 3 \mathrm{a} \\
\mathrm{H} 3 \mathrm{~b}\end{array}$} & POS $>$ CWB-I & -0.192 & -0.203 & 0.065 & 2.958 & 0.003 & -0.315 & -0.066 & Supported \\
\hline & POS $>$ CWB-O & -0.221 & -0.236 & 0.070 & 3.167 & 0.002 & -0.363 & -0.090 & Supported \\
\hline
\end{tabular}

Note. EOHRM =Employee oriented HRM;POS=Perceived organizational support ; $C W B-I=$ counter productive work behavior -individual; $C W B-O=$ counter productive work behavior-organizational $; N S=$ not supported . Endogenous latent Variable $R^{2}=\boldsymbol{C W B}-\mathbf{I}: 0.127, \boldsymbol{C W B}-\boldsymbol{O}: 0.137$, POS: 0.530; Endogenous latent Variable $Q^{2}=\boldsymbol{C W B}-\mathbf{I}: 0.108, \boldsymbol{C W B - O}: 0.112, \boldsymbol{P O S}: 0.248$; 
Table 5: Hypothesis Testing- Indirect Effect

\begin{tabular}{|c|c|c|c|c|c|c|c|c|c|}
\hline \multirow{2}{*}{ 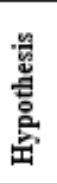 } & \multirow[b]{2}{*}{ Relationships } & \multirow{2}{*}{$\begin{array}{l}\text { Original } \\
\text { Sample } \\
\text { (0) }\end{array}$} & \multirow{2}{*}{$\begin{array}{l}\text { Beta } \\
\text { coefficient }\end{array}$} & \multirow{2}{*}{$\begin{array}{l}\text { Standard } \\
\text { Deviation } \\
\text { (STDEV) }\end{array}$} & \multirow{2}{*}{$\begin{array}{l}\text { T Statistics } \\
(|\mathrm{O} / \mathrm{STDEV}|)\end{array}$} & \multirow{2}{*}{$\begin{array}{l}\mathbf{P} \\
\text { Values }\end{array}$} & \multicolumn{2}{|c|}{$\begin{array}{r}\text { Confidence } \\
\text { interval Bias } \\
\text { corrected [ upper } \\
\text { and lower limit] }\end{array}$} & \multirow[t]{2}{*}{ Inferences } \\
\hline & & & & & & & $2.50 \%$ & $97.50 \%$ & \\
\hline $\mathrm{H} 4 \mathrm{a}$ & $\begin{array}{l}\text { EO-HRM }>\text { POS }> \\
\text { CWB-I }\end{array}$ & -0.139 & -0.148 & 0.048 & 2.888 & 0.004 & -0.232 & -0.048 & Full mediation \\
\hline $\mathrm{H} 4 \mathrm{~b}$ & $\begin{array}{l}\text { EO-HRM }>\text { POS }> \\
\text { CWB-O }\end{array}$ & -0.16 & -0.172 & 0.051 & 3.122 & 0.002 & -0.266 & -0.066 & Full mediation \\
\hline
\end{tabular}

Note. EOHRM =Employee oriented HRM;POS=Perceived organizational support; CWB-I= counter productive work behavior -individual; $C W B-O=$ counter productive work behavior-organizational

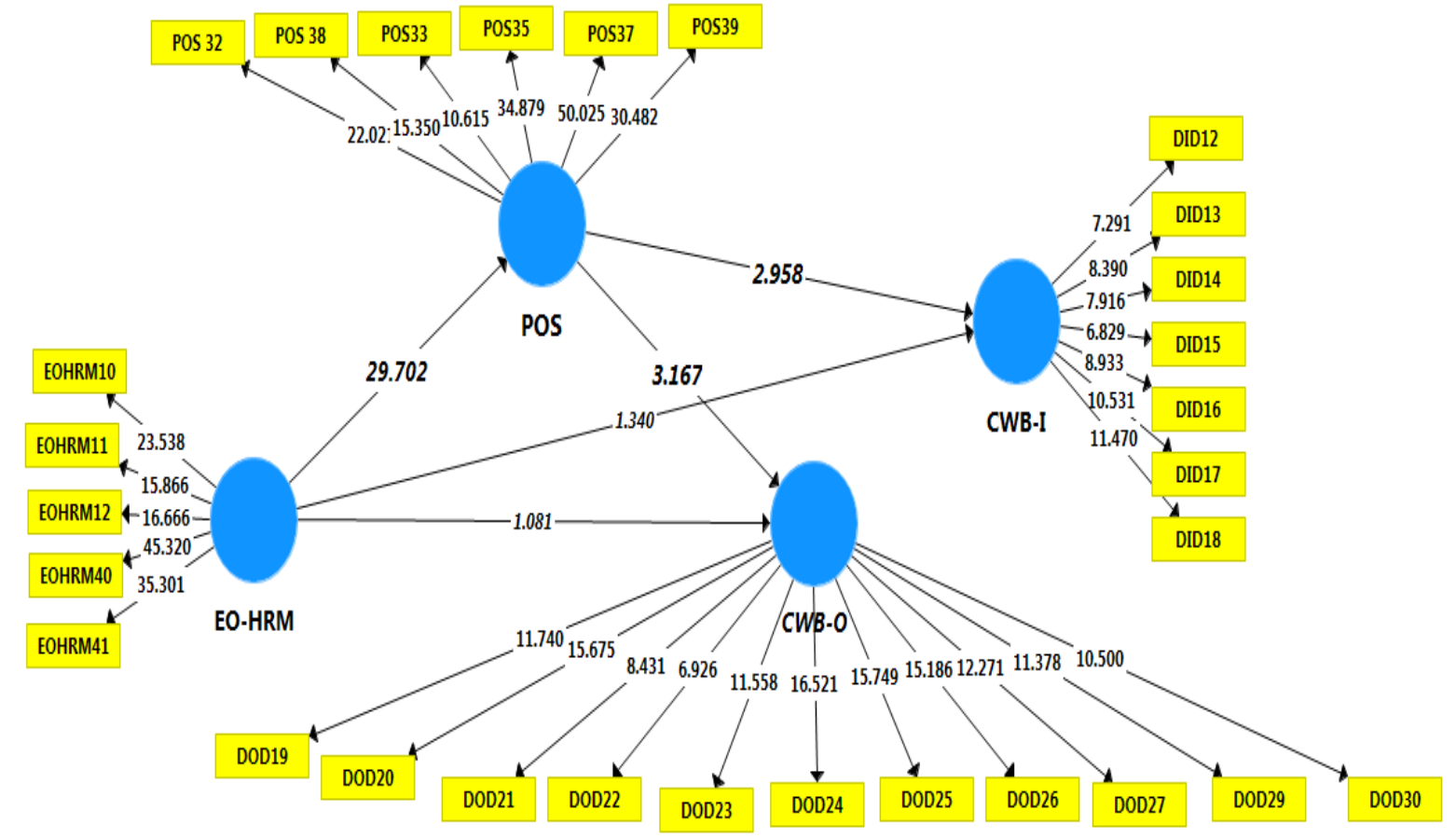

Figure 2: Structural Model.

Note. $C W B-I=$ Counterproductive work behavior-individual ; $C W B-0=$ Counterproductive work behaviororganizational ; EOHRM =Employee oriented HRM;POS=Perceived organizational support. 


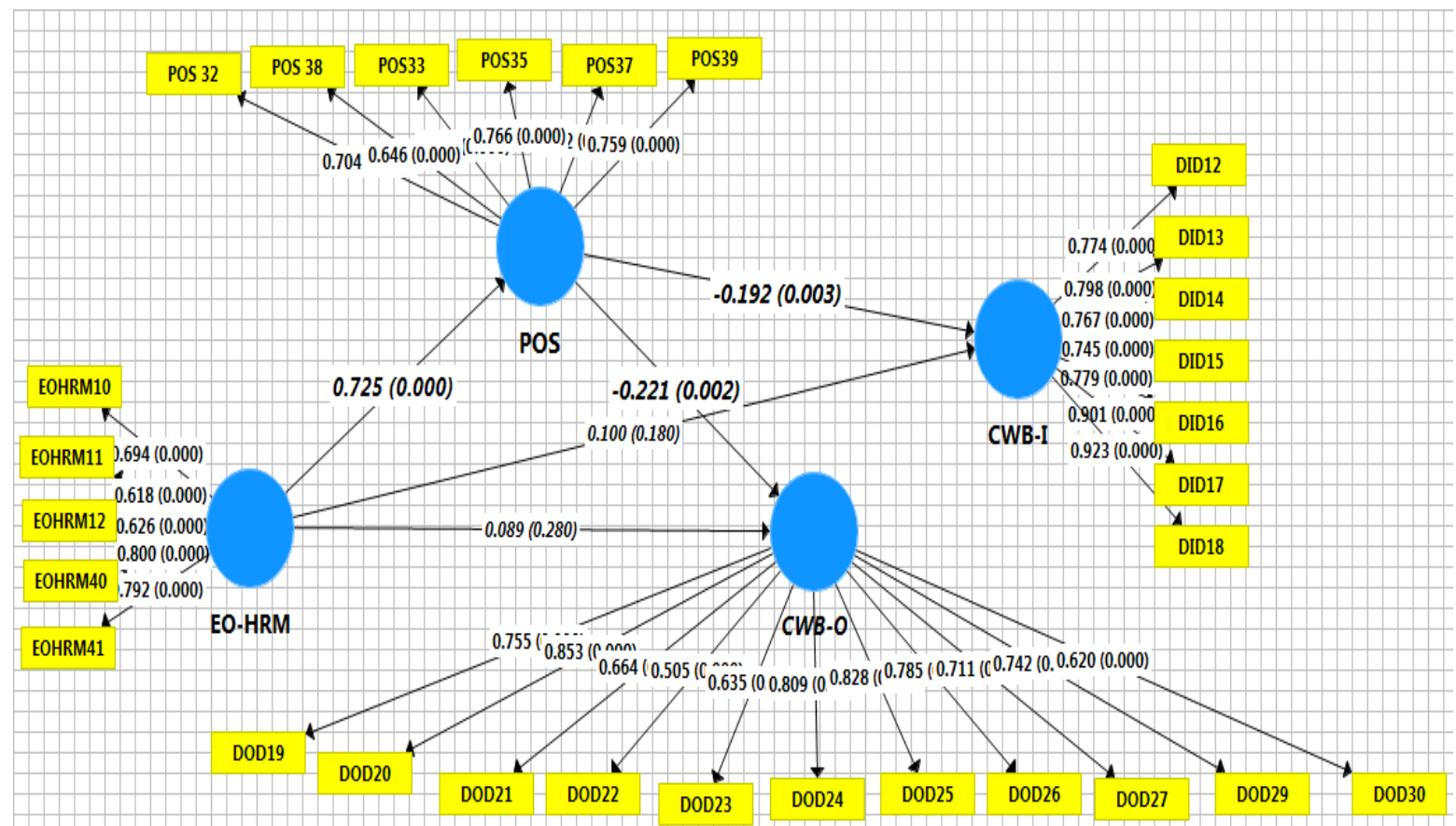

Figure 3: PLS-Path Analysis of Bootstrapping - Inner Model Path Coefficients and $P$ value along with Outer Model Outer Weight /Loadings and $P$ value

Note. $C W B-I=$ Counterproductive work behavior-individual $; C W B-0=$ Counterproductive work behaviororganizational $; E O H R M=$ Employee oriented HRM;POS=Perceived organizational support.

\section{Discussion}

This research explored the role of employee oriented human resource management practices in minimizing (tackling) counterproductive work behavior among employees in Ethiopia. In contrast to anticipations, this research failed to obtain a significant negative connection between EO-HRM and counterproductive work behaviors(CWB -I \&O). However, this study verifies a strong and full mediation of POS in the link between EOHRM and CWBs geared towards individual and organization.

Alternatively, the results of this research disclosed a strong association between EO-HRM and perceived organizational support. This outcome is in line with findings of earlier study by Shore \& Shore (1995) who mentioned that people management strategies that focus on rewarding employees valued input would ultimately uplift the level of perceived organizational support. Social exchange theory likewise backed the finding by arguing employees feeling of POS determines the types of their attitudes and ultimately their attitudes determines the type of their behavioral tendencies(Blau 1964). As a result, workers see some encouraging and unhelpful conduct from their companies, then they build up some pleasant and unfavorable attitudes and eventually display some behaviors depending on these attitudes(yildiz \& Alpkan 2015).

Furthermore, the results of this research also pointed out a significant negative relationship between perceived organizational support and counterproductive work behavior targeted both at individual and organization. This finding is in accordance with results of earlier investigation that portrayed the negative connection between perceived organizational support and counterproductive work (Eder \& Eisenberger 2008; Colbert et al. 2004; Ferris et al. 2009; Ferris et al. 2009; Hochwarter et al. 2003; Shanock \& Eisenberger 2006; Thau et al. 2009).

Additionally, our findings shows that perceived organizational support acts as a mediator in between EOHRM \& counterproductive work behavior targeted both at individual and organization(CWB-I \&O). But the impact of EOHRM on counterproductive work behavior -organizational via perceived organizational support were stronger than the impact of EOHRM on counterproductive work behavior- individual (interpersonal). Turker (2018) elaborated that innovative bundles of EOHRM practices entails provisions of support for overall health of both workers and pensioners, establishing innovative childcare alternatives, forming baby-inclusive work set up that grant to workers the right to bring their young children, and arrangement of remote working for the parents who have children that needs attention. Availability of such bundles of EO-HRM shows the commitment of the company in establishing their social responsibility towards staff members and their families. In exchange, the recognized beneficial treatment creates a noticed accountability to worry about the company's wellbeing and to ensure that the company accomplishes its targets as suggested by social exchange theory and norm of reciprocity (Eisenberger et al. 2002). 
In our hypothesis development, we stated perceived organizational support just as one root system that may support to explain how EOHRM techniques could decrease the tendency to involve in counterproductive work behaviors. Evidently, the outcomes of this study renders scientific backing to link EOHRM to perceived organizational support \& CWB geared towards individual and organization. This finding is in accordance with results of prior research by Shin et al. (2017) which concludes that employees' perceptions of organizational efforts to satisfy their responsibilities further than the maximization of profit(philanthropic responsibilities towards employees), act as a deterrent shield against employees' counterproductive behavior. This indicates that when companies give more focus on integrate EOHRM practices within their strategy, they will likely succeed in dealing with the extent of counterproductive work behaviors targeted both at individual and organization.

\section{Implications}

Based on aforesaid outcomes, there are handful of suggestions and ramifications for human resources managers and top management of organizations. Theoretically, this research has provided a couple of empirical proof relating to the relationship among employee-oriented HRM practice, perceived organizational support and CWBI (individual targeted) and CWB-O (organization-targeted). Among the basic theoretical implication of this study is the inclusion of perceived organizational support as a mediator to clarify connection in between employeeoriented HRM practice and counterproductive work behavior targeted at individual and organization. The results of this investigation have likewise add values to literature on counterproductive work behavior. The study results confirmed that employee-oriented HRM routines are vital elements uplifting employees POS which intern reduce the tendency of workers to commit counterproductive work behaviors.

Additionally, this research provides useful tips for managers in organizations. We learned that workers employed in an organization that put into action EOHRM practices build a long lasting impression of perceived organizational support and thereby tend not to participate in counterproductive behavior against their particular company and co-workers. This implies at least two approaches for forestalling counterproductive behavior at work. First, managers should specifically figure out which of their workers needs that falls outside the legal requirement needs instant attention based upon proper investigation. This would allow managers to develop a philanthropic bundles towards their workers that address the most crucial ones.

Taking into consideration the relevance of perceived organizational support as the proximal negative predecessor of counterproductive work behavior geared towards individual and organization, a second plan of action should be to enhance the degree of employees' perceived organizational support in order to protect against CWB -I and O more directly. As shown in this research, POS lessens the possibilities of counterproductive work behavior (CWB-I\&O). Hence, in addition to prioritizing the employees needs which are beyond the legal requirement and addressing them, it is beneficial for a company to learn the best practice with regard to EOHRM practices from others. Companies are at different stages in the continuum of philanthropic bundles provided to employees. Some organizations has minimum bundle and others offer more sophisticated philanthropic bundles. For instance, top rated companies in social responsibility towards employees formulated in-house projects towards their employees; like, support for the overall health of both their current staff members and pensioners, furnished outlandish daycare options, established remote working for parents that have infants that requires particular attention, and launched a baby-inclusive working arrangement (Turker 2018). By doing so, once the organization became successful in driving the bar of perceived organizational support high; employees will reciprocate towards the organization by involving more on constructive behavior and withholding their engagement in counterproductive work behaviors.

Finally, the result of this study corroborate the idea that investment in people pays more return than pouring more resources in technology with regards to preventing against counterproductive work behaviors (Lavion \& others 2018). Although technology is obviously an important device in preventing against counterproductive work behaviors, it can only be part of the solution(Lavion \& others 2018). One of the most important element in decision to commit counterproductive work behavior is eventually human behavior- and working in control these part by means of putting into action heightened employee oriented philanthropic bundles payoff more.

\section{Limitations and future directions}

This research has some shortcomings that indicate areas for foreseeable future study prospects. First of all, the current research concentrated primarily on analyzing POS as the only mediating mechanism; nevertheless, there are other psychological processes by which EOHRM approaches may possibly impact counterproductive work behaviors. Therefore, forthcoming studies may possibly include the other variables such as commitment, employee engagement, and organizational citizenship behavior when examining the links between EOHRM practices and employees' CWBs.

Secondly, this research primarily used a cross-sectional technique which does not allow causal inferences to be made from the population. Thus, upcoming research have to concentrate on multilevel analysis, longitudinal data, and "big" data(Ones 2018). 
Thirdly, for this research the data had been gathered from companies situated in the capital city of EthiopiaAddis Ababa, because of time constraints and monetary limitations. Furthermore, this research incorporates only eight organizations who showed readiness to take part in the research. Consequently, upcoming studies can be stretched to other locations in Ethiopia as well as broaden its focus on surveys takers form varied companies spanning numerous sector to be able to conduct comparative analysis.

Finally, in the present study, CWBs was examined utilizing supervisors evaluations of the degree to which they have noticed their staff involved in each of the counterproductive behavior in the last year. In process of data collection the researchers come to realize that the supervisors were resistant to fill the questionnaires correctly after reading the content despite the fact that anonymity was reassured throughout the data collection. The majority of the supervisors thought that they are mainly accountable for controlling their staff members behavior and they try to under rate the their employees counterproductive behavior frequency to be in safe side. That is primarily to keep positive image of their organization and to guard their position as a good manager. Due to this problem, a number of filled questioners had been discarded as most supervisors ratings had been characterized by suspicious response patterns. To minimize this problem, forthcoming study should acquire data from multiple sources. More specifically, it is beneficial to see the comparative variation of associations when self-reports (admissions) compared to other reports (e. g., supervisory and peer ratings) are used (Ones 2018).

\section{References}

Alfes, K. et al., 2013. The link between perceived human resource management practices, engagement and employee behaviour: a moderated mediation model. The international journal of human resource management, 24(2), pp.330-351.

Alias, M. et al., 2013. Predictors of workplace deviant behaviour: HRD agenda for Malaysian support personnel. European Journal of Training and Development, 37(2), pp.161-182.

Appelbaum, S.H., Iaconi, G.D. \& Matousek, A., 2007. Positive and negative deviant workplace behaviors: causes, impacts, and solutions. Corporate Governance: The international journal of business in society, 7(5), pp.586-598.

Ashforth, B.E., Harrison, S.H. \& Corley, K.G., 2008. Identification in Organizations: An Examination of Four Fundamental Questions. Journal of Management, 34(3), pp.325-374.

Ashforth, B.E. \& Mael, F.A., 1989. Social Identity Theory and the Organization. Academy of Management Review, 14(1), pp.20-39.

Bennett, R.J., Marasi, S. \& Locklear, L., 2018. Workplace Deviance. Oxford Research Encyclopedia of Business and Management.

Bennett, R.J. \& Robinson, S.L., 2000. Development of a measure of workplace deviance. Journal of applied psychology, 85(3), p.349.

Blau, P.M., 1964. Exchange and power in social life. New Brunswick.

Burns, A.C., Bush, R.F. \& Sinha, N., 2014. Marketing research, Pearson Harlow.

Cohen, J., 1988. Statistical power analysis for the behavioral sciences 2 nd edn.

Colbert, A.E. et al., 2004. Interactive effects of personality and perceptions of the work situation on workplace deviance. Journal of Applied Psychology, 89(4), p.599.

Connelly, B.L. et al., 2011. Signaling theory: A review and assessment. Journal of Management, 37(1), pp.3967.

Cotterell, N., Eisenberger, R. \& Speicher, H., 1992. Inhibiting effects of reciprocation wariness on interpersonal relationships. Journal of Personality and Social Psychology, 62(4), pp.658-668.

Cropanzano, R. et al., 2016. Social exchange theory: A critical review with theoretical remedies. Academy of Management Annals, pp.1-107.

Cropanzano, R. \& Mitchell, M.S., 2005. Social Exchange Theory: An Interdisciplinary Review. Journal of Management, 31(6), pp.874-900.

Detert, J.R. et al., 2007. Managerial modes of influence and counterproductivity in organizations: A longitudinal business-unit-level investigation. Journal of Applied Psychology, 92(4), p.993.

Dunlop, P.D. \& Lee, K., 2004. Workplace deviance, organizational citizenship behavior, and business unit performance: The bad apples do spoil the whole barrel. Journal of Organizational Behavior: The International Journal of Industrial, Occupational and Organizational Psychology and Behavior, 25(1), pp.67-80.

Dutton, J.E. \& Dukerich, J.M., 1991. Keeping An Eye on the Mirror: Image and Identity In Organizational Adaptation. Academy of Management Journal, 34(3), pp.517-554.

Dutton, J.E., Dukerich, J.M. \& Harquail, C.V., 1994. Organizational images and member identification. Administrative Science Quarterly, 39(2), pp.239-263.

Eder, P. \& Eisenberger, R., 2008. Perceived organizational support: Reducing the negative influence of coworker withdrawal behavior. Journal of Management, 34(1), pp.55-68. 
Eisenberger, R. et al., 1986. Perceived organizational support. Journal of Applied Psychology, 71(3), pp.500-507.

Eisenberger, R. et al., 2002. Perceived supervisor support: Contributions to perceived organizational support and employee retention. Journal of Applied Psychology, 87(3), pp.565-573.

Ferris, D.L., Brown, D.J. \& Heller, D., 2009. Organizational supports and organizational deviance: The mediating role of organization-based self-esteem. Organizational Behavior and Human Decision Processes, 108(2), pp.279-286.

Galperin, B.L., 2002. Determinants of deviance in the workplace: An empirical examination in Canada and Mexico.

Gould-Williams, J., 2007. HR practices, organizational climate and employee outcomes: evaluating social exchange relationships in local government. The International Journal of Human Resource Management, 18(9), pp.1627-1647.

Greenberg, J., 1990. Organizational Justice: Yesterday, Today, and Tomorrow. Journal of Management, 16(2), pp.399-432.

Hair Jr, J.F. et al., 2016. A primer on partial least squares structural equation modeling (PLS-SEM), Sage Publications.

Hair Jr, J.F. et al., 2017. A primer on partial least squares structural equation modeling (PLS-SEM), Sage Publications.

Hannah, D. \& Iverson, R., 2004. Employment relationships in context: Implications for policy and practice. The employment relationship: Examining psychological and contextual perspectives, pp.332-350.

Hochwarter, W.A. et al., 2003. Perceived organizational support as a mediator of the relationship between politics perceptions and work outcomes. Journal of Vocational Behavior, 63(3), pp.438-456.

Khan, A.K., Quratulain, S. \& Crawshaw, J.R., 2013. The mediating role of discrete emotions in the relationship between injustice and counterproductive work behaviors: A study in Pakistan. Journal of business and psychology, 28(1), pp.49-61.

Kroll, 2016. Global Fraud Report: Vulnerabilities on the Rise annual edition, ed., the economist and intelligence unit.,

Lavion, D. \& others, 2018. Pulling fraud out of the shadows. PwC's.

Mostafa, A.M.S. \& Gould-Williams, J.S., 2014. Testing the mediation effect of person -organization fit on the relationship between high performance HR practices and employee outcomes in the Egyptian public sector. The International Journal of Human Resource Management, 25(2), pp.276-292.

Newman, A. et al., 2016. The impact of socially responsible human resource management on employees' organizational citizenship behaviour: the mediating role of organizational identification. The International Journal of Human Resource Management, 27(4), pp.440-455.

Ones, D.S., 2018. Counterproductive work behaviors 2.0: Assessment or consequences. International Journal of Selection and Assessment, 26(1), pp.1-4.

Ones, D.S. \& Dilchert, S., 2013. Counterproductive work behaviors: Concepts, measurement, and nomological network.

Podsakoff, P.M. et al., 2003. Common method biases in behavioral research: a critical review of the literature and recommended remedies. Journal of applied psychology, 88(5), p.879.

Rasool, I., 2017. Impact of Perceived External and Internal Corporate Social Responsibility on Organizational Citizenship Behavior: A Moderated Mediated Model.

Rhoades, L., Eisenberger, R. \& Armeli, S., 2001. Affective commitment to the organization: The contribution of perceived organizational support. Journal of applied psychology, 86(5), p.825.

Rhoades, L., Eisenberger, R. \& others, 2002. Perceived organizational support: A review of the literature. Journal of applied psychology, 87(4), pp.698-714.

Ringle, C.M., Sarstedt, M. \& Straub, D., 2012. A critical look at the use of PLS-SEM in MIS Quarterly.

Robinson, S.L. \& Bennett, R.J., 1995. A typology of deviant workplace behaviors: A multidimensional scaling study. Academy of management journal, 38(2), pp.555-572.

Salancik, G.R. \& Pfeffer, J., 1978. A social information processing approach to job attitudes and task design. Administrative science quarterly, pp.224-253.

Shanock, L.R. \& Eisenberger, R., 2006. When supervisors feel supported: relationships with subordinates' perceived supervisor support, perceived organizational support, and performance. Journal of Applied psychology, 91(3), p.689.

Shen, J. \& Benson, J., 2016. When CSR is a social norm: How socially responsible human resource management affects employee work behavior. Journal of Management, 42(6), pp.1723-1746.

Shen, J. \& Jiuhua Zhu, C., 2011. Effects of socially responsible human resource management on employee organizational commitment. The International Journal of Human Resource Management, 22(15), pp.30203035 .

Shin, I. et al., 2017. Hidden Roles of CSR: Perceived Corporate Social Responsibility as a Preventive against 
Counterproductive Work Behaviors. Sustainability, 9(955), pp.1-12. Available at: http://www.mdpi.com/2071-1050/9/6/955.

Shore, L.M. \& Shore, T.H., 1995. Perceived organizational support and organizational justice. Organizational politics, justice, and support: Managing the social climate of the workplace, 149, p.164.

Snape, E. \& Redman, T., 2010. HRM practices, organizational citizenship behaviour, and performance: A multilevel analysis. Journal of management studies, 47(7), pp.1219-1247.

Spence, M., 1973. Job market signaling. The quarterly journal of Economics, 87(3), pp.355-374.

Sun, L.-Y., Aryee, S. \& Law, K.S., 2007. High-performance human resource practices, citizenship behavior, and organizational performance: A relational perspective. Academy of management Journal, 50(3), pp.558-577.

Thau, S. et al., 2009. How management style moderates the relationship between abusive supervision and workplace deviance: An uncertainty management theory perspective. Organizational Behavior and Human Decision Processes, 108(1), pp.79-92.

Turker, D., 2018. Social Responsibility and Human Resource Management. In Managing Social Responsibility. Springer, pp. 131-144.

Vatankhah, S., Javid, E. \& Raoofi, A., 2017. Perceived organizational support as the mediator of the relationships between high-performance work practices and counter-productive work behavior: Evidence from airline industry. Journal of Air Transport Management, 59, pp.107-115.

Viswesvaran, C., Deshpande, S.P. \& Milman, C., 1998. The effect of corporate social responsibility on employee counterproductive behavior. Cross Cultural Management: An International Journal, 5(4), pp.5-12.

yildiz, B. \& Alpkan, L., 2015. A theoretical model on the proposed predictors of destructive deviant workplace behaviors and the mediator role of alienation. Procedia-Social and Behavioral Sciences, 210, pp.330-338. 